\title{
Studies On Extracting Microcystin-Lr From Microcystis Aeruginosa By Water Bath ${ }^{*}$
}

\author{
Fang Li, Wenqing Liu, Nanjing Zhao", Jingbo Duan, Zhigang Wang, Yujun Zhang, Xue Xiao, \\ Jing Liu, Gaofang Yin, Chaoyi Shi
}

Key Laboratory of Environmental Optics and Technology, Anhui Institute of Optics and Fine Mechanics, Chinese Academy of Sciences, 350 Shu Shan Hu Road, Hefei, Anhui, China.

Email: ${ }^{n}$ jzzhao@aiofm.ac.cn

Received 2013

\begin{abstract}
Different temperatures of water bath was used to extract the intracellular microcystin-LR(MC-LR) of Microcystis aeruginosa. Researching the extraction efficiency under the suitable temperature, so that it could find out the best temperature and time for extracting MC-LR from Microcystis aeruginosa cells. Five equal Microcystis aeruginosa was used to find out the best temperature, extracting at $60^{\circ} \mathrm{C}, 70^{\circ} \mathrm{C}, 80^{\circ} \mathrm{C}, 90^{\circ} \mathrm{C}$ and $100^{\circ} \mathrm{C}$ for 15 minutes, respectively. Results showed that the content of MC-LR extracted with the water under $100^{\circ} \mathrm{C}$ was the highest. But meanwhile, the type and the content of impurities was the highest, too. In addition, another six equal Microcystis aeruginosa was extract with the water under $100^{\circ} \mathrm{C}$ for $5 \mathrm{~min}, 10 \mathrm{~min}, 15 \mathrm{~min}, 20 \mathrm{~min}, 25 \mathrm{~min}$ and $30 \mathrm{~min}$ respectively. It was proved that 20 minutes was enough for extracting MC-LR from Microcystis aeruginosa, no long time was needed.
\end{abstract}

Keywords: Boiling Water Bath; Extract; Microcystin-LR

\section{Introduction}

Cyanobacteria bloom happens more and more frequently worldwide because of growing pollution, causing many kinds of microcystins(MCs) which have drawn much public attention. MCs, which could be detected in 80 percent water bloom according to the survey, can inhibit the activity of protein phosphatase(1, 2Aand3), promote oncogenesis, or even lead to death.

MCs are ring peptide compounds composition of seven amino acid. They are very stable and release into water body after the cellular ruptured, causing serious harm to the water quality and aquatic. There're more than 80 different microcystins according to the data has been already reported. At present, the research of MCs has been focuses on the toxicology, environmental chemistry, preparation of standard toxins used for analysis and the applications in biochemistry, etc. It can't obtain MCs from chemical synthesis. So that extracting MCs from toxigenic strains efficiently becomes the basis and prerequisite of the study of MCs.

At present there're many methods to extract MCs from

"Foundation item: The national "863" project grants program (2009AA063005); Natural science fund projects in anhui province (11040606M26); Anhui institute of optics and fine mechanics, director of the project fund (Y03AG31144).

${ }^{\#}$ Corresponding author. cellular. ZHANG Ming-ming [1] used 40\% methanol solution as the extract solvent, thawing and refreezing cells repeatly to extract microcystin-LR(MC-LR). REN Jing's results showed that it was efficient to use $75 \%$ methanol as extract solvent, freezing and thawing the cells as well as ultrasonication. Because cyanobacteria belongs to prokaryotes, the cell wall is mainly mucopeptide, so that both cryogenically freezing and boiling can destroy cell wall and then MCs released. But freezing and thawing resulted in low toxin and time consuming. The research of Jarkko Rapala [3] showed that after the first freezing and thawing only a small number of cyanobacteria colonies had been dispersed. Sonication for 60 min in the water bath disrupted only the outermost cells of the colonies. After the second freezing and thawing and sonication for 15 min a high number of unbroken cells was still seen. Using methanol to extract MCs, it must dilute the extract solvent by water or heat and volatile the extract solvent to reduce the concentration of the methanol before solid phase extraction. This increases the time of solid phase extraction, and the use of organic regents is bad to the health of the researchers. In addition, many organics such as phycobiliprotein in cyanobacteria cells, which could be extracted with MCs, may pollute the column of the chromatographic. Some reported that using guard columns to remove the protein, and then 
elute MCs. Some adjusted the PH value to 4 with diluted solution of sulfuric acid, so that the protein was denaturation and precipitated and the column was defended from pollution. All these methods was time consuming and increased the cost. Metcalf et al. [5] first extracted MCs with boiling water, using deionized water as extraction solvent. The result showed that one minute was very good for $150 \mu \mathrm{L}$ extraction solvent. The use of boiling water based upon the heat resisitance of MCs. MCs would not lose activity after heating in the water of $100^{\circ} \mathrm{C}$ for $30 \mathrm{~min}$, and was hard to resolve under $300^{\circ} \mathrm{C}$ [6]. This method avoided the use of methanol during the extraction process which was unsafe to the analyst. In addition, it lowered the cost, and shortened the time of extraction. LEI La-mei et al [7] also studied extracting MCs with boiling water, and contrasted with the traditional method using methanol, found that the relative error was between $0.2 \%$ and $16.59 \% .12$ min of heating time was enough in their study and deionized water was better than distilled water for the extraction of MCs.

In conclusion, the use of boiling water to extract MCs from cyanobacteria cells has a good application prospect. But at present this method is not very mature as there are not many related reports. This study systematically researched extracting MC-LR within the cells of Microcystis aeruginosa, obtaining the best temperature and time. And good results had been achieved with the recovery of $89.3 \%$. A great quantity of organic solvent was avoid during the extraction process. The entire analysis could be finished in one day.

\section{Material and Method}

\subsection{Instruments}

The main instruments needed in this experiment were as follows: Visiprep SPE Vacuum Manifold-DL, 24-port model; Supelclean ENVI-18 cartridges $(500 \mathrm{mg} / 3 \mathrm{~mL})$; Agilent 1200 HPLC (Eclipse XDS-C18 chromatographic column); HP400G incubator(Wuhan Ruihua Instrument \& Equipment Co.Ltd); Molecular ultra-pure water machine; sterilizer; The Labnet 6Liter Water Bath; H-1650 Ultracentrifuge; NMT-2800 Pressure Blowing Concentrator.

\subsection{Reagent}

The main reagents are as follows: methanol (chromatographic grade), trifluoroacetic acid (TFA, chromatographic grade); deionized water; phosphoric acid; 0.05 $\mathrm{mol} / \mathrm{L} \quad \mathrm{KH}_{2} \mathrm{PO}_{4}$ (chromatographic grade); Microcystis aeruginosa(FACHB-905) was purchased from institute of hydrobiology, Chinese academy of sciences and cultured in BG-11 medium.

\subsection{Extraction of MC-LR}

\subsubsection{The Experiment of Selecting the Best Temperature}

Added 10 equal parts of Microcystis aeruginosa which were in logarithmic growth phase into 10 Erlenmeyer flasks, centrifuging and removing the supernatant. The cells were transferred into other 10 Erlenmeyer flasks with deionized water. Then put them into water bath at $60^{\circ} \mathrm{C}, 70^{\circ} \mathrm{C}, 80^{\circ} \mathrm{C}, 90^{\circ} \mathrm{C}$ and $100^{\circ} \mathrm{C}$, respectively. Two parallel samples were managed for each temperature. After 15 minutes took them out and centrifuged, the supernatant was transferred into 10 clean Erlenmeyer flasks, respectively. Washing the residue with deionized water and centrifuged again, combining the supernatant. The supernatant were loaded into SPE cartriege, rinsed with $10 \mathrm{~mL}$ deionized water and $20 \%$ methanol, and then the MC-LR was eluted by $90 \%$ methanol which containing $0.1 \%$ TFA). The eluents were dried under nitrogen in $40^{\circ} \mathrm{C}$ water bath, the rest substances was dissolved in 0.5 $\mathrm{mL}$ methanol(two times) and transferred into autosampler vial, dried again with stream of nitrogen, diluted with $50 \%$ methanol to $200 \mu \mathrm{L}$, and detected by HPLC.

\subsubsection{The Extracting Time under $100^{\circ} \mathrm{C}$}

Added 12 equal parts of Microcystis aeruginosa which were in logarithmic growth phase into 12 Erlenmeyer flasks. The isolation of cells was the same as the above. The flasks were put into $100^{\circ} \mathrm{C}$ for $5 \mathrm{~min}, 10 \mathrm{~min}, 15 \mathrm{~min}$, $20 \mathrm{~min}, 25 \mathrm{~min}$ and $30 \mathrm{~min}$, respectively. Two parallel samples for each gradient. The crude extract was centrifuged and loaded into SPE as above.

\subsection{HPLC Conditions}

Column temperature at $40^{\circ} \mathrm{C}$, using methanol and the buffer solution of phosphoric acid $(\mathrm{PH}=3)$ at $57: 43(\mathrm{~V} / \mathrm{V})$ as the mobile phases, velocity of flow was $1 \mathrm{~mL} / \mathrm{min}$, wavelength of the UV-vis detectors was $380 \mathrm{~nm}$.

\section{Results and Discussion}

The contents of MC-LR extracted under different temperature were showed in Figure 1. The algae cells were extracted 15 minutes under each temperature. As it turned out, the higher the temperature, the much MC-LR was extracted. In the range of $70^{\circ} \mathrm{C}$ to $100^{\circ} \mathrm{C}$, the content of MC-LR and the temperature had a good linear relationship. The data showed that every $10^{\circ} \mathrm{C}$ degree temperature rise would increase the content of MC-LR about $15 \mu \mathrm{g} / \mathrm{L}$. Thus it could be seen that the appropriate temperature for extracting MC-LR from Microcystis aeruginosa was $100^{\circ} \mathrm{C}$. But the disadvantage was that the pigments and other impurities in the algae cells would extracted out simultaneously. These impurities would interfere with the detection of MC-LR. Research about eliminating influence from these impurities is continuing. 
The results of extracting MC-LR for six different times in $100^{\circ} \mathrm{C}$ water bath was shown in Figure 2. It demonstrated that the content of MC-LR was the highest when extracted for $20 \mathrm{~min}$. For 5 minutes, it was too short that a large amount of cells were still integrity, so the MC-LR inside the cells couldn't be released. If the time was too long, part of the MC-LR was degraded under the high temperature, resulting in the reducing of the content of MC-LR.

\section{Conclusion}

Tests results showed that there were some advantages to extract MC-LR from Microcystis aeruginosa cells by water bath, listing as follows: firstly, it was quick, convenient and reducing the costs. The whole procedure could be finished in one day. Secondly, the denaturation of protein under high temperature made it no need to adjust $\mathrm{PH}$ value with sulfuric acid. Thirdly, this method avoided the use of methanol during the extracting proc-

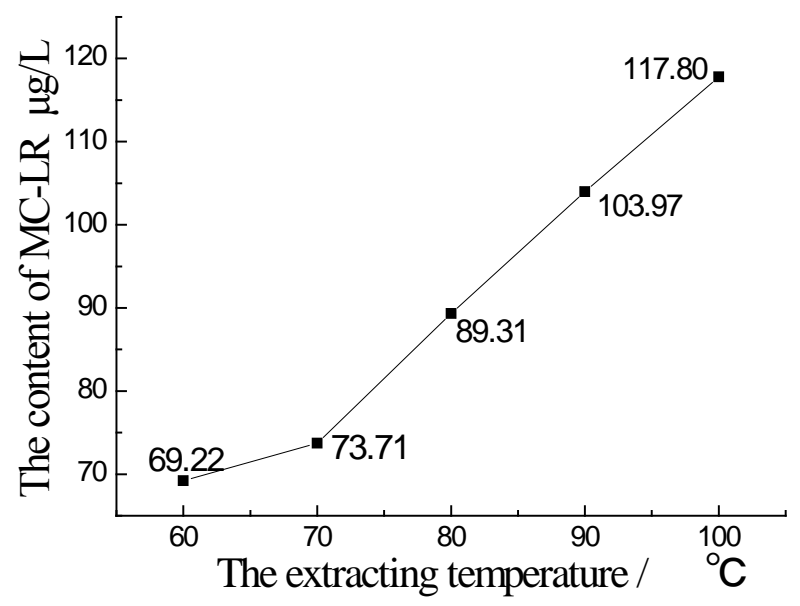

Figure 1. Results of extracting MC-LR under different temperature.

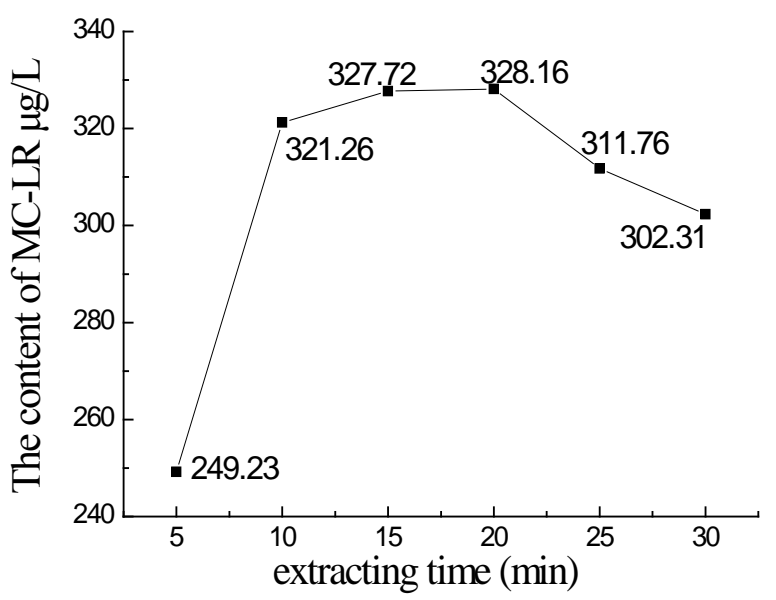

Figure 2. The time of extracting MC-LR from Microcystis aeruginosa under $100^{\circ} \mathrm{C}$. ess and therefore reduced injuries to researchers. This experiment demonstrated it was valid to extract MC-LR from the cells of Microcystis aeruginosa under $100^{\circ} \mathrm{C}$ for 20 minutes. The recovery was over 89.3\%. Even so, there are some problems, namely meanwhile the pigments and other impurities would be extracted out, which could interfere with the determination of MC-LR. Experiments had been designed, attempting to remove the impurities by gradient rinsing the column with different levels of methanol, namely water, $10 \%, 20 \%, 30 \%$, and $40 \%$ methanol. Resulting that methanol below the concentration of $30 \%$ couldn't remove the pigments. But $40 \%$ methanol would elute a large part of MC-LR. So it was obviously unsatisfactory to remove the impurities with different concentrations of methanol. In addition, the time of extracting MC-LR might relate to the consumption of the deionzed water for suspending the algae cells and the density of the cells. This had to be studied further and comprehensively. At the moment, there were not many data for extracting MCs with boiling water bath. As this method had a promising prospect it should be continually studied and improved.

\section{Acknowledgements}

We should like to express our sincere thanks to the editors and the reviewers for their useful comments. This study is supported by the funds as follows: National “863” Program of China(2009AA063005), Anhui Provincial Natural Science Foundation(11040606M26), Foundation of Director of Anhui Institute of Optics and Fine Mechanics (Y03AG31144), and this is gratefully acknowledged.

\section{REFERENCES}

[1] ZHANG Ming-ming,PAN Gang,YAN Hai et al.A method to extract algae toxin of microcystin-LR[J].Journal of Environmental Sciences. 16(4):694-696.(2004)

[2] REN Jing, WANG Xiang-rong, HAO Meng-li. Optimization of extracting microcystins in the cells of Microcystis aeruginosa with HPLC. Sciencepaper Online.

[3] Jarkko Rapala, Kirsti Erkomaa, Jaana Kukkonen et al. Detection of microcystins with protein phosphatase inhibition assay, high-performance liquid chromatography-UV detection and enzyme-linked immunosorbent assay Comparison of methods. Analytica Chimica Acta. 466:213-231.(2002)

[4] TANG Hong-feng, SUN Qian, MU Ting et al. The comparison of extracting microcystins in natural water bloom cyanobacteria[J]. Chemistry \& Bioengineering. 28(1):82-84.(2011)

[5] James S.Metcalf,Geoffrey A.Codd.Microwave oven and boiling waterbath extraction of hepatotoxins from cyanobacterial cells.FEMS Microbiology Letters. 184: 241246.(2000) 
[6] LI Qiu-xia, CAI Chao-hai, XU Gui-lan. Rapid detection of microcystins-LR in drinking water with super fast performance liquid chromatography-tandem mass spectrometry. Chin J Health Lab Technol. 20(8): 1875- 1877. (2010)
[7] LEI La-mei, Gan Nan-qin, SONG Li-rong. A rapid method to extract and analyse microcystins. ACTA Hydrobiologica Sinica. 27(5):468-471.(2003)

[8] National Standards of Peoples Republic of China. GB/T 20466-2006. The detection of microcystins in water. 